HELMINTHOLOGIA, 53, 2: 126 - 132, 2016

\title{
Detrimental effects of geldanamycin on adults and larvae of Trichinella spiralis
}

\author{
A. A. OTHMAN* ${ }^{*}$ Z. S. SHOHEIB
}

Department of Medical Parasitology, Faculty of Medicine, Tanta University, Tanta, Egypt, ${ }^{\star} E m a i l:$ ahmed_ali44@hotmail.com

\section{Article info}

Received December 3, 2015 Accepted February 22, 2016

\begin{abstract}
Summary
Trichinellosis is a zoonotic disease affecting mainly the temperate regions. The treatment is a challenge for the physician, and the available therapy is far from ideal. Therefore, this work aimed to evaluate the effect of heat shock protein 90 inhibitor, geldanamycin, on the adult worms and larvae of Trichinella spiralis. This research comprised an in vivo study in which $T$. spiralis-infected mice were treated by two different doses of geldanamycin, thereafter larval count and pathological changes were determined in the muscles. Meanwhile, the in vitro study investigated the effect of two different concentrations of geldanamycin on adult worms and larvae of $T$. spiralis via transmission electron microscopy. The in vivo study showed significant reduction of muscle larval counts under the effect of geldanamycin. Moreover, characteristic changes were noted as regards the parasite and the inflammatory response. The in vitro study revealed degenerative changes in the body wall of larvae and adults of $T$. spiralis under the influence of geldanamycin. In conclusion, heat shock protein 90 inhibitor, geldanamycin, seems to have detrimental effects on the adults and larvae of $T$. spiralis. It, or one of its derivatives, could be an adjuvant to anthelmintic therapy of trichinellosis, but more studies are warranted to establish its usefulness.
\end{abstract}

Keywords: Trichinella spiralis; Geldanamycin; Heat shock proteins; Electron microscopy

\section{Introduction}

Trichinellosis is a zoonotic disease affecting mainly temperate regions; many cases were reported all over the world including Egypt. Trichinella spiralis (T. spiralis) has a complex life cycle where the adults reside in the small intestine while the encysted larvae in skeletal muscle cells within the same host. Trichinellosis can be associated with severe neurological, ocular, and cardiovascular complications and may end fatally. The treatment is a challenge for the physician. It is most effective when administered early in the course of the disease (Gottstein et al., 2009).

Heat shock proteins (HSPs) are widely distributed in nature. They perform important functions in the folding and unfolding or translo- cation of proteins, as well as in the assembly and disassembly of protein complexes. The heat shock response is a general homeostatic mechanism that protects cells and the entire organism from the deleterious effects of environmental stress. In non-stressed cells, HSPs are present in low concentration, while in stressed cells they accumulate at high levels (Zügel \& Kaufmann, 1999). The parasites protect themselves against the host by activating various evasion mechanisms including HSP synthesis (Buchmeier \& Heffron, 1990). Apparently, HSPs play specific functions in differentiation of parasites, in protection from the host killing mechanisms, including free radicals, and even in virulence (Devaney, 2006).

Heat shock protein 90 (HSP90) functions as a part of a multi-pro- 
tein complex that promotes the folding and stability of client proteins. It is essential for survival of nematodes as confirmed in Brugia malayi (Selkirk et al., 1989), Caenorhabditis elegans (Birnby et al., 2000), and T. spiralis (Martinez et al., 2004; Yang et al., 2014). Geldanamycin (GA), a natural product produced by Streptomyces hygroscopicus, is a specific inhibitor of HSP90 (Grenert et al., 1997). GA binding alters the conformation of HSP90 in such a way as to destabilize client proteins, which are then targeted for degradation via the proteasome (Whitesell et al., 1998). In vitro, GA exhibits deleterious effects on many biological systems including bacteria, viruses, and nematodes. Furthermore, some of its derivatives are in phase II clinical trials for the chemotherapy of certain tumours (Neckers \& Neckers, 2002). Interestingly, Yang et al. (2014) has reported that the expression of TsDAF-21/HSP90 protein was attenuated by GA treatment of muscle larvae of $T$. spiralis.

This study aimed to evaluate the effect of HSP90 inhibitor, GA, on the adult worms and larvae of $T$. spiralis.

\section{Materials and Methods}

\section{Parasite and animals}

Mice were infected with $T$. spiralis L1 larvae orally (Despommier et al., 1977; Dunn \& Wright, 1985). The strain of T. spiralis was isolated from infected pork meat obtained from Cairo abattoir and maintained in the laboratory of Medical Parasitology department, Tanta Faculty of Medicine by consecutive passages through rats and mice. The Trichinella isolate used in this study was genotyped as T. spiralis by the European Union Reference Laboratory for Parasites, Superior Institute of Health, Rome, Italy. Male Swiss albino mice, 6 - 8 weeks old, weighing $25-30 \mathrm{~g}$ each were used. The animals were purchased from Theodore Bilharz Research Institute (Giza, Egypt) and were housed in appropriate cages and fed with a commercial rodent chow and tap water ad libitum, in accordance with the institutional and national guidelines.

\section{Drug}

Geldanamycin $\left(\mathrm{C}_{29} \mathrm{H}_{40} \mathrm{~N}_{2} \mathrm{O}_{9}\right.$, M.W. 560.64) was obtained from LC Laboratories, a division of PKC Pharmaceuticals, Inc. The drug was supplied as yellow microcrystalline powder. GA was dissolved in $0.1 \%$ dimethyl sulfoxide (DMSO) to give a stock of $10 \mathrm{mM}$ to be used in animals and in vitro studies.

\section{In vivo experiment}

Twenty one mice were infected by $250 \mathrm{~T}$. spiralis larvae each. Briefly, the infective larvae were obtained from infected stock Swiss mice by $1 \%$ pepsin $/ 1 \% \mathrm{HCl}$ digestion (Dunn \& Wright, 1985). Two groups of seven animals received GA at a dose of 0.5 and $1 \mathrm{mg} /$ $\mathrm{kg}$ by intraperitoneal injection once every other day to give a total of 3 doses. Treatment started at $7^{\text {th }}$ day p.i. The remaining mice served as a control infected group. Additional seven infected mice received only DMSO. At 35 days p.i., the animals were euthanized, and muscle larvae were recovered and counted as described before (Dunn \& Wright, 1985).

Similar parts of the diaphragm and thigh muscles were obtained and processed for histopathological examination by (H\&E) and periodic acid-Schiff (PAS) staining. The PAS reaction was carried out as described elsewhere (Lechler et al., 2007). Briefly, the deparaffinized sections were rehydrated in a series of degraded alcohols to distilled water, rinsed in $70 \% \mathrm{EtOH}$, placed in aldehyde fuchsin for $15 \mathrm{~min}$, rinsed in alcoholic bisulfite solution, counterstained, and washed in $70 \% \mathrm{EtOH}$, dehydrated, cleared, and permanently mounted.

\section{In vitro evaluation of $G A$}

Adult worms were recovered (Wakelin \& Lloyed, 1976). Briefly, mice were infected orally by 250 Trichinella L1 larvae. After 48 $\mathrm{h}$ the animals were killed, the small intestine removed, cut into pieces, and kept in phosphate-buffered saline for $4 \mathrm{~h}$ of incubation at $37^{\circ} \mathrm{C}$. The female adult worms were collected in test tubes. GA was then added and diluted in PBS to the appropriate concentration $(0.5 \mu \mathrm{M}$ or $1.0 \mu \mathrm{M})$. Controls included worms incubated with the appropriate volume of carrier DMSO or PBS. Worms were incubated at $37^{\circ} \mathrm{C}$ in an atmosphere of $5 \% \mathrm{CO}_{2}$ in air. Samples of worms were taken after $6 \mathrm{~h}$ and $24 \mathrm{~h}$ of incubation and processed for electron microscopy.

Muscle larvae were obtained from infected mice as described before (Dunn \& Wright, 1985), and placed in PBS in a test tube. The larvae were then treated by GA exactly as described for adults.

\section{Preparation for electron microscopic examination}

Briefly, the parasites (larvae or adults) were transferred to $1-\mathrm{ml}$ centrifuge tubes. The tubes were centrifuged at $7,000 \mathrm{~g}$ for $1 \mathrm{~min}$, and the parasites were resuspended in modified Karnovsky's fixative $(1.25 \%$ glutaraldehyde and $20 \%$ paraformaldehyde in 0.1 $\mathrm{M}$ phosphate buffer, $\mathrm{pH} 7.0$ ) and fixed at $4{ }^{\circ} \mathrm{C}$ for 3 days. The aldehyde fixative was removed using an overnight wash of $0.1 \mathrm{M}$ phosphate at a pH of 7.0; this and all the other solution changes made prior to the addition of agar as described below were done by centrifuging the parasites at 7,000 $\mathrm{g}$ for $1 \mathrm{~min}$ and suspension in a new solution. The parasites were post-fixed for $1 \mathrm{~h}$ in $1 \%$ osmium tetroxide and then washed twice with 2 10-min changes of distilled water. After removing the water from the second wash, a small portion of $2 \%$ agar, about $150 \mu \mathrm{l}$, at $55-60{ }^{\circ} \mathrm{C}$ was added to the pellet of the parasites. After the agar hardened, it was removed from the tubes and cut into small blocks (Bowman et al., 1993). Blocks of parasites were dehydrated using a graded ethanol series and then infiltrated with the plastic embedding mixture of Mollenhaeur (1964). Sections were cut using Ultracut microtome and were mounted on mesh grids. Sections were stained by uranyl acetate and were examined by electron microscope. Photographs were recorded on Kodak electron image plates (Mollenhauer, 1964). 

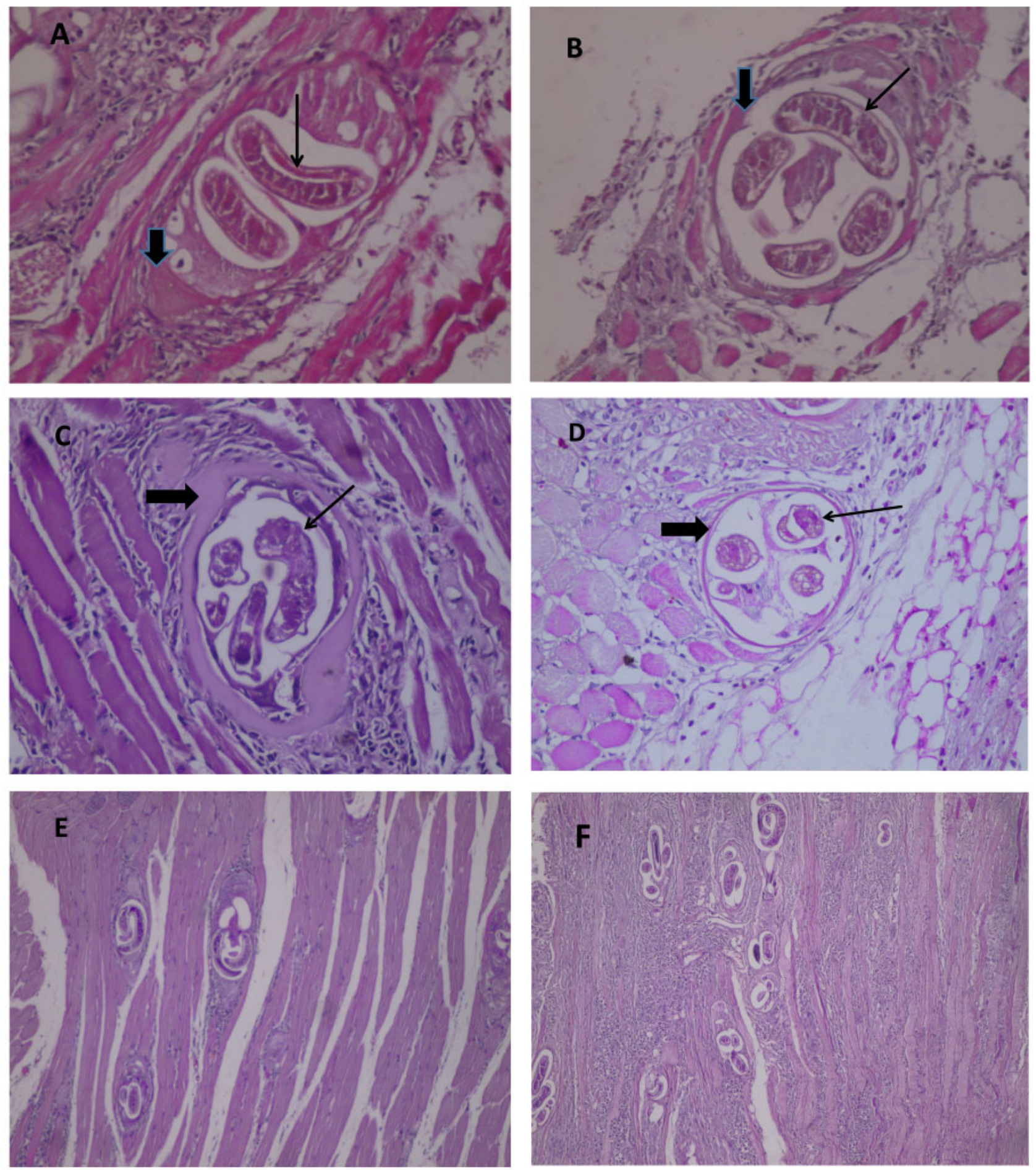

Fig. 1. Photomicrographs of skeletal muscle sections 5 weeks p.i. showing: A,C encapsulated larvae from the control infected mice. The collagenous capsule (thick arrow) surrounds sections of Trichinella larvae (thin arrow) (PAS, H\&E $\times 400)$. B,D thinning of the capsule (thick arrow) around the larvae (thin arrow) in the treated mice (PAS, H\&E $\times 400)$. E, mild to moderate inflammatory reactions around larvae in the control group (H\&E $\times 100)$. F, moderate to marked intensity of inflammation around the encapsulated larvae and in between muscle fibres in the treated group (H\&E ×65) 


\section{Statistical Analysis}

Data were presented as mean \pm standard deviation. The probability of significant differences among dual means of groups was determined by Student's $t$-test. Differences were considered non-significant when $(P>0.05)$, significant $(P<0.05)$, and highly significant $(P<0.001)$. The statistical analyses were processed according to the conventional procedures using Statistical Program of Social Sciences (SPSS) software for windows, version 10.0.

\section{Results}

In vivo study

\section{Muscle larval burden}

No difference was found between control infected animals $(25,428 \pm 1,397)$ and DMSO-treated infected animals $(26.221 \pm 453)$ as regards the muscle larval count. In contrast, significant reduction of larval counts was observed in the treated groups compared to control animals. Moreover, there was significant difference between the groups treated with GA. The larval reduction rate was of $40.4 \%$ in low dose $(0.5 \mathrm{mg} / \mathrm{kg})$, whereas that of the higher dose $(1 \mathrm{mg} / \mathrm{kg}$ ) was of $67.9 \%$ (Table 1).

Table 1. Muscle larval count in control and treated groups

\begin{tabular}{cccc}
\hline & Control $(n=7)$ & Group 1 $(n=7)$ & Group 2 $(n=7)$ \\
\hline Mean \pm SD & $25,428 \pm 1,397$ & $15,428 \pm 975$ & $8,142 \pm 1,069$ \\
IE & ------ & $40.4 \%$ & $67.9 \%$ \\
F. test & 14.526 & \\
P. value & 0.001 & \\
\hline Control \& G1 & Control \& G2 & G1 \& G2 \\
0.001 & 0.001 & 0.001 \\
\hline
\end{tabular}

Intensity effect (IE): IE $(\%)=[(N-n) / N] \times 100$

Where $\mathrm{N}$ is the average number of larvae in control group and $\mathrm{n}$ is the average number of larvae in treated groups.

Group 1 received low dose of $\mathrm{GA}(0.5 \mathrm{mg} / \mathrm{kg})$, while group 2 received higher dose $(1 \mathrm{mg} / \mathrm{kg})$.

\section{Histopathological examination}

Muscle sections from mice receiving the solvent showed similar changes as in control animals. The striking changes observed in PAS or ordinary (H\&E) staining was thinning of the capsule around Trichinella encapsulated larvae in the treated groups (Fig. 1A D). Moreover, despite the presence of larvae with no surrounding inflammatory reaction in both treated and untreated groups, the number of larvae surrounded by inflammatory infiltrates was significantly higher $(P>0.05)$ in the treated groups. Moreover the intensity of inflammation seemed to be higher in the treated groups (Fig. 1E,F).
In vitro study

As regards the adult worms, the control group showed the characteristic structure of the cuticle being composed of two layers: upper striated and electron dense layer, and lower non-striated and electron light one. The cuticle is surrounded by the wavy two-layered epicuticle (Fig. 2A). In the treated groups the following changes were observed: a) haziness or blunting of the epicuticle which is the only change observed in lower dose of GA (Fig. 2B), b) loss of the electron dense layer of the cuticle (Fig. 2B), c) separation of the cuticle from the underlying hypodermis either in small areas forming blebs or extending through a large area (Fig. 2C), d) washed-out image of the cytoplasm of the hypodermis denoting cell damage (Fig. 2C,D).

As regards the larvae, the cuticle in the control group was composed of two major regions separated by an electron dense layer. The outer surface of the cuticle was bounded by 4 electron dense layers (Fig. 2E). In the treated groups the changes were less striking consisting mainly of disruption of layers 3 and 4 (Fig. 2F).

\section{Discussion}

The medical treatment of trichinellosis is problematic as there are "areas of uncertainty". The classical medical treatment includes benzimidazole anthelmintics (mebendazole or albendazole) combined with steroids. Mebendazole is usually administered at a daily dose of $5 \mathrm{mg} / \mathrm{kg}$ but higher doses (up to $20 \mathrm{mg} / \mathrm{kg} /$ day to $25 \mathrm{mg} /$ $\mathrm{kg} /$ day) are recommended in some countries. Albendazole is used at $800 \mathrm{mg} /$ day $(15 \mathrm{mg} / \mathrm{kg} / \mathrm{day})$ administered in two doses. These drugs should be taken for 10 to 15 days (Bruschi \& Dupouy-Camet 2014). The main problem in treatment is the poor susceptibility of migrating and encapsulated muscle larvae to anthelmintic drugs, making late treatment far from ideal (Gottstein et al., 2009). Moreover, combinations of anthelmintics with steroids delay the convalescent period and in severe cases this may provoke coagulopathic disorders, infrequently fatal haemorrhages (Ozeretskovskaia \& Sergiev, 1994).

Heat shock proteins are best characterized for their role in cell survival during periods of stress, where their ability to bind denatured or misfolded proteins is essential for survival (Morimoto, 1998). HSPs also function during normal growth and division as chaperones for protein folding and transport. HSPs are essential for the survival of nematodes. For example, HSP70 has been found to be expressed in $T$. spiralis and has been found to help resist the environmental stress imposed on the parasite by the inflammatory reaction elicited by the host immune cells (Salem et al., 2001; Martinez et al., 2002). HSP90 is unique amongst the family of heat shock proteins because of the specific nature of the proteins with which it interacts under non-stress conditions. These include a range of signalling and receptor molecules with important roles in cell division, cell cycle, and apoptosis (Aligue et al., 1994; de Cárcer et al., 2001). Notably, HSP90 has been found essential for the survival of many parasitic filarial nematodes (Devaney et 

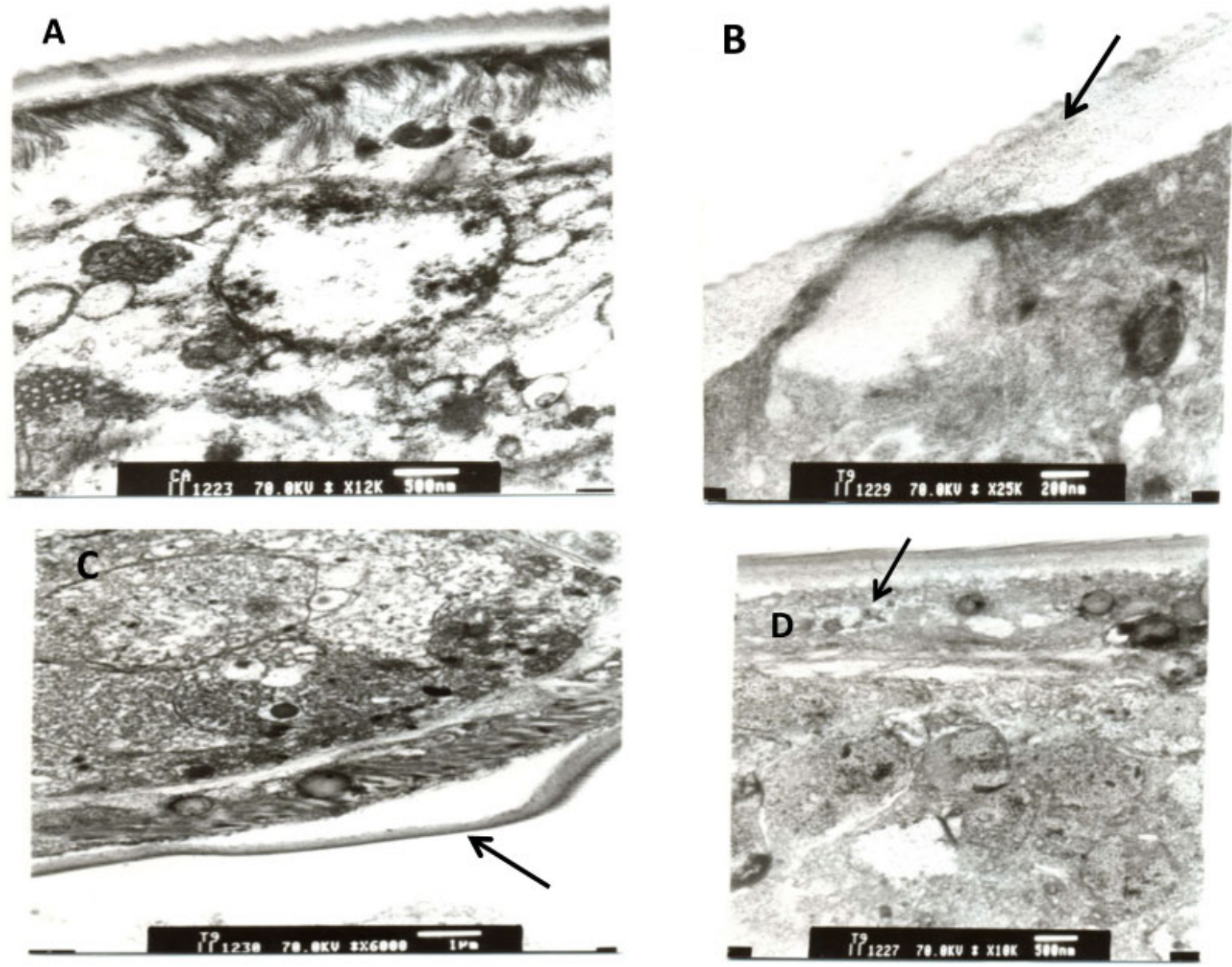

$\mathbf{E}$
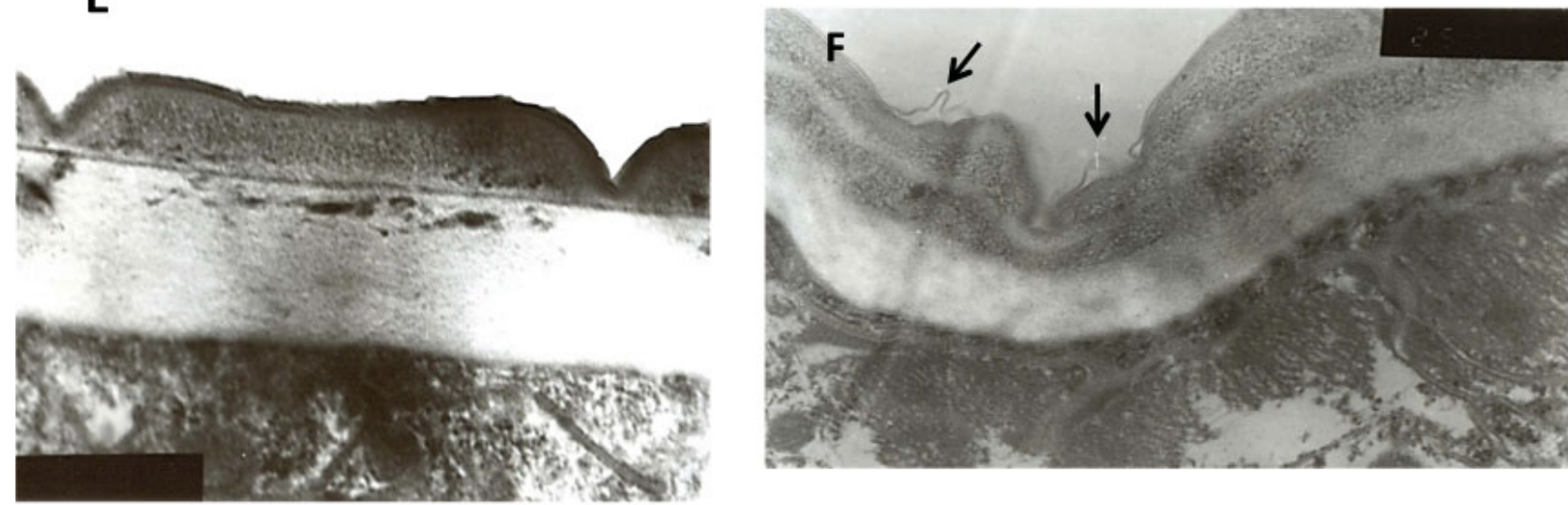

Fig. 2. Electron micrographs of the body wall of adult worms $(A-D)$ and larvae $(E, F)$ : $A$, section in the body wall of an adult from control infected mouse $(\times 12,000)$. $B$, loss of the electron dense layer in the cuticle (arrow) is observed $(\times 25,000)$. C, separation of the cuticle from the underlying hypodermis (arrow) is noted ( $\times 6000)$. $\mathrm{D}$, there are blunting of the epicuticle and washed-out image of the cytoplasm (arrow) $(\times 10,000)$. E, section in the cuticle of a larva from the control group $(\times 20,000)$. $\mathrm{F}$, disruption of the layers of the cuticle (arrows) is noted $(\times 25,000)$ 
al., 2005), and has been found to be expressed in all examined life cycle stages of $T$. spiralis (Yang et al., 2013). Therefore, the present study aimed at investigating whether HSP90 could be a novel target for the chemotherapy of trichinellosis.

Our study demonstrated the lethal effect of HSP90 inhibitor, geldanamycin, on the parasitic stages of $T$. spiralis. Both doses of GA produced significant reduction in total muscle larval count. This could be due to effect on adults or larvae or both. The effect on the muscle larvae is deduced from the presence of thinner capsules and marked inflammatory reaction in treated mice denoting immunopathological response secondary to larval damage. The effect on the adult worms cannot be ruled out as the drug was found to affect the worms in our in vitro study. Similarly, another study demonstrated that GA kills adult worms and microfilariae (Mf) of Brugia pahangi at nanomolar concentrations. In addition, release of Mf from adult worms is inhibited within $24 \mathrm{~h}$ of exposure to GA and is not recoverable, demonstrating that GA effectively sterilizes the worms. Similar results were obtained with a second filarial worm Acanthocheilonema viteae (Devaney et al., 2005).

The body wall of a typical nematode consists of the cuticle, the hypodermis, and the somatic musculature. Integrity of nematode cuticle is essential for the nutritive and protective functions as well as to maintain shape. It provides protection from physical or immunological injury, and plays a role in osmoregulation (Roberts \& Janovy, 2013). The electron microscopy in our study demonstrated damage of the cuticle and hypodermis especially in adult worms. This may shed some light upon the mechanism of action of GA. In a similar way, Toxocara canis adults exposed to albendazole show severe morphological alterations in the body wall which contributes to the lethal effect of the drug (Shalaby et al., 2009). The limitation of our in vitro study is the short time of incubation of the parasite, beyond which the internal organs might have showed signs of damage.

T. spiralis larvae in the muscles are surrounded by a collagenous capsule which is induced by the parasite and synthesized by the host as a part of nurse cell formation. Capsule formation is a complex process involving several types of cells with formation of collagen fibers. This capsule is thought to serve a protective function to the larvae (Alford et al., 1998; Sacchi et al., 2001). Therefore, there have been attempts to target this capsule e.g., by use of antifibrotic agents (Shoheib et al., 2006), or cytotoxic drugs (Campbell \& Blair, 1975) in order to enhance the effect of specific anthelmintics. In our study, the muscle larvae in GA-treated mice show thinning of the capsule. This may allow more facilitated ingress of the inflammatory cells or perhaps enhanced diffusion of anthelmintics. This could add to the direct lethal effect of the drug and make it a potentially useful adjuvant therapy.

During the life cycle of Trichinella, there exists an intense mitotic activity whether in adult worms for production of newborn larvae, or in the muscle-stage larvae during nurse cell formation which involves cell proliferation and formation of new vessels. Therefore, unsurprisingly, cytotoxic or antimitotic drugs have been tried in the treatment of experimental trichinellosis. However, these drugs, including methotrexate and cyclophosphamide, showed limited success (Campbell \& Blair, 1975). Perhaps the antimitotic activity of these drugs on the parasite was offset by their immunosuppressive action on host immune cells. Fortunately, GA showed significant lethal effect in experimental trichinellosis, and could be a promising adjuvant to anthelmintics.

This study demonstrated the detrimental effects of GA against adults and larvae of $T$. spiralis. The drug itself is not suitable for human use due to its poor solubility and hepatotoxicity. However, its derivatives are more soluble and less hepatotoxic, and are already employed in ongoing phases of clinical trials for treatment of malignancy (Tatokoro et al., 2015). Therefore, further studies are warranted on one or more of GA derivatives to assess the potential use in therapy of trichinellosis.

In conclusion, HSP90 seems to be essential for the survival of different stages of $T$. spiralis as the HSP90 inhibitor, GA, exhibited detrimental effects against the different stages of $T$. spiralis. The drug, or one of its derivatives, could be a useful adjuvant to specific anthelmintic therapy. Our findings are of importance given the fact that the number of drugs available against this parasite is quite limited. Further studies are needed to elucidate the full parasitocidal effects of the drug as well as the useful dosage and duration of treatment.

\section{Acknowledgements}

The authors are most grateful to Prof. Takahashi Y., Professor Emeritus, Gifu University, Japan, for helping in interpretation of the electron micrographs, and also to Prof. Mohamed M. Shareef, Professor of Pathology, Tanta Faculty of Medicine, Egypt, for his aid in assessment of the histopathology.

\section{References}

Alford, K., Obendorf, D.L., Fredeking, E., Haehling, E., Stewart, G.L. (1998): Comparison of the inflammatory responses of mice with American and Australian Trichinella pseudospiralis or Trichinella spiralis. Int. J. Parasitol., 28: 343 - 348. DOI: 10.1016/ S0020-7519(97)00184-7

Aligue, R., Akhavan-Niak, H., Russell, P. (1994): A role for Hsp90 in cell cycle control: Wee1 tyrosine kinase activity requires interaction with Hsp90. EMBO J., 13: 6099 - 6106

Birnby, D.A., Link, E.M., Vowels, J.J., Tian, H., Colacurcio, P.L., THOMAS, J.H. (2000): A trans-membrane guanylylcyclase (DAF-11) and $\mathrm{Hsp} 90$ (DAF-21) regulate a common set of chemosensory behaviors in Caenorhabditis elegans. Genetics, 155: $85-104$

Bowman, D.D., OAKs, J.A., GRIEVE, R.B. (1993): Ultrastructure of the infective-stage larva of Toxocara canis (Nematoda: Ascaridoidea). J. Helminthol. Soc. Wash., 60: $183-204$

Bruschl, F., Dupouy-Camet, J. (2014): Trichinellosis. In Bruschi, F. (Ed) Helminth infections and their impact on global public health. Springer-Verlag Wien. pp. 229 - 273. DOI 10.1007/978-3-70911782-8_8 
Buchmeier, N.A., Heffron, F. (1990): Induction of Salmonella stress proteins upon infection of macrophages. Science, 248: 730 - 732. DOI: 10.1126/science.1970672

CAmpBell, W.C., BlaiR, L.S. (1975): Failure to confirm reported lethal effect of cytotoxic drugs on encapsulated Trichinella spiralis larvae in mice. J. Parasitol., 61: 1116 - 1117

de Cárcer, G., do Carmoavides, M., Lallena, M.J., Glover, D.M., GonZÁlez, C. (2001): Requirement of Hsp90 for centrosomal function reflects its regulation of Polo kinase stability. EMBO J., 20: $2878-2884$

Despommier, D.D., Campbell, W.C., Blair, L.S. (1977): The in vivo and in vitro analysis of immunity to Trichinella spiralis in mice and rats. Parasitology, 74(1):109 - 119

Devaney, E. (2006): Thermoregulation in the life cycle of nematodes. Int. J. Parasitol., 36: 641 - 649. DOI: 10.1016/j.jjpara.2006.02.006

Devaney, E., O'neill, K., Harnett, W., Whitesell, L., Kinnaird, J.H. (2005): Hsp90 is essential in the filarial nematode Brugia pahangi. Int. J. Parasitol., 35: 627 - 636. DOI: 10.1016/j.jpara.2005.01.007 DunN, I.J., WRIGHT, K.A. (1985): Cell injury caused by Trichinella spiralis in the mucosal epithelium of B10 A mice. J. Parasitol., 71: $757-766$

Gottstein, B., Pozıo, E., Nöckler, K. (2009): Epidemiology, diagnosis, treatment, and control of trichinellosis. Clin. Microbiol. Rev., 22: 127 - 145. DOI: 10.1128/CMR.00026-08

Grenert, J.P., Sullivan, W.P., Fadden, P., Haystead, T.A., Clark, J., Mimnaugh E., Krutzsch, H., Ochel, H.J., Schulte, T.W., Sausville, E., Neckers, L.M., Toft, D.O. (1997): The amino-terminal domain of heat shock protein 90 (hsp90) that binds geldanamycin is an ATP/ADP switch domain that regulates hsp90 conformation. The $J$. Biol. Chem., 272: 23843 - 23850. DOI: 10.1074/jbc.272.38.23843 Lechler, P., Wu, X., Bernhardt, W., Campean, V., Gastiger, S., Hackenbeck, T., Klanke, B., Weidemann, A., Warnecke, C., Amann, K., Engehausen, D., Willam, C., Eckardt, K.U., Rödel, F., WiesenER, M.S. (2007): The tumor gene survivin is highly expressed in adult renal tubular cells: implications for a pathophysiological role in the kidney. Am. J. Pathol., 171: 1483 - 1498. DOI: 10.2353/ ajpath.2007.070132

Martinez, J., Perez-Serrano, J., Bernadina, W.E., Rodriguez-CaabelRo, F. (2002): Expression of Hsp90, Hsp70 and Hsp60 in Trichinella species exposed to oxidative shock. J. Helminthol., 76: 217 223. DOI: $10.1079 / \mathrm{JOH} 2002127$

Martinez, J., Perez-Serrano, J., Bernadina, W.E., Rincon, I., RodriGUEZ-CAABEIRO, F. (2004): Heat shock protein synthesis over time in infective Trichinella spiralis larvae raised in suboptimal culture conditions. J. Helminthol., 78: 243 - 247. DOI: 10.1079/JOH2003225 Mollenhauer, H.H. (1964): Plastic embedding mixtures for use in electron microscopy. Stain Technol., 39: 111 - 114

Morimoto, R.I. (1998): Regulation of the heat shock transcriptional response: cross talk between a family of heat shock factors, molecular chaperones, and negative regulators. Genes Dev., 12: 3788 - 3796. DOI: 10.1101/gad.12.24.3788
NeCKers, L., NeCKERS, K. (2002): Heat-shock protein 90 inhibitors as novel cancer chemotherapeutic agents. Expert Opin. Emerg. Drugs, 7: 277 - 288. DOI: 10.1517/14728214.7.2.277

Ozeretskovskaia, N.N., Sergiev, V.P. (1994): The specific and biological actions of chemical preparations and their combination with pathogenic agents in trichinosis. Med. Parazitol., 4: 9 - 14

RoberTs, L.S., Janovy, J., Nadler, S. (2013): Nematodes: Trichinellida and Dioctophymatida, Enoplean Parasites. In: Schmidt G.D. \& Roberts L.S.'s Foundations of Parasitology. 9th edition. McGrawHill, New York, USA. pp. $381-388$

Sacchi, L., Corona, S., Gajadhar, A.A., Pozio, E. (2001): Ultrastructural characteristics of nurse cell- larva complex of four species of Trichinella in several hosts. Parasite, 8(Suppl): S54 - S58. DOI: 10.1051/parasite/200108s2054

Salem, S.A., El-Kowrany, S.I., Ismall, H.I., El-SheikH, T.F. (2001): Study on the possible role of heat shock proteins in host resistance to Trichinella spiralis infection in experimental animals. J. Egypt. Soc. Parasitol., 31: 133 - 144

Selkirk, M.E., Denham, D.A., Partono, F., Maizels, R.M. (1989): Heat shock cognate 70 is a prominent immunogen in Brugian filariasis. J. Immunol., 143: 299 - 308

Shalaby H.A., Abdel-Shafy S., Abdel-Rahman K.A., Derbala A.A. (2009): Comparative in vitro effect of artemether and albendazole on adult Toxocara canis. Parasitol. Res., 105, 967 - 976. DOI: 10.1007/s00436-009-1479-9.

Shoheib, Z.S., Shamloula, M.M., Abdin, A.A., El-Segal, O. (2006): Role of a-chemotrypsin and colchicine as adjuvant therapy in experimental muscular trichinellosis: Parasitological, biochemical, and immunohistochemical study. Egypt. J. Med. Microbiol., 15: $773-789$

TAtokoro, M., Koga, F., Yoshida, S., Kihara, K. (2015): Heat shock protein 90 targeting therapy: state of the art and future perspective. EXCLI J., 14: 48 - 58. DOI: 10.17179/excli2015-586

WAKELIN, D., LLOYED, M. (1976): Immunity to primary and challenge infection of Trichinella spiralis in mice, a re- examination of conventional parameters. Parasitology, 71: 173 - 182. DOI: http:// dx.doi.org/10.1017/S0031182000048472

Whitesell, L., Sutphin, P.D., Pulcini, E.J., Martinez, J.D., Cook, P.H. (1998): The physical association of multiple molecular chaperone proteins with mutant p53 is altered by geldanamycin, an hsp90-binding agent. Mol. Cell. Biol., 18: 1517 - 1524. DOI: 10.1128/MCB.18.3.1517

ZÜGEL, U., KaUfMANn, S.H. (1999): Role of heat shock proteins in protection from and pathogenesis of infectious diseases. Clin. Microbiol. Rev., 12: 19 - 39

YANG, Y., QIn, W., Zarlenga, D., CAO, L., Tian, G. (2013): TsDAF-21/ Hsp90 is expressed in all examined stages of Trichinella spiralis. Vet. Parasitol., 194: 171 - 174. DOI: 10.1016/j.vetpar.2013.01.048. YANG, Y., QIN, W., QIU, H., LIU, Y. (2014): Characterization of TsDAF-21/HSP90 protein from the parasitic nematode Trichinella spiralis. Parasitol. Res., 113: 2209 - 2217. DOI: 10.1007/s00436014-3874-0 